\title{
Untethered lives: barriers to societal integration as predictors of the sexual orientation disparity in suicidality
}

\author{
Richard Bränström ${ }^{1,2}\left(\mathbb{D} \cdot\right.$ Arjan van der Star $^{1,2} \cdot$ John E. Pachankis ${ }^{1}$
}

Received: 21 December 2018 / Accepted: 24 June 2019 / Published online: 12 July 2019

(c) The Author(s) 2019

\begin{abstract}
Purpose Despite increasing legal protections and supportive attitudes toward sexual minorities (e.g., those who identify as lesbian, gay, and bisexual [LGB]) in recent decades, suicidality remains more common among this population than among heterosexuals. While barriers to societal integration - or a lack of meaning, purpose, and belonging as derived from societal norms, goals, and attachment—have been widely theorized as determinants of suicidality for the general population, they have not been comprehensively explored to explain the sexual orientation disparity in suicidality. The aim of this study was to examine differences in suicidal ideation and attempts between LGB and heterosexual individuals in a nationally representative sample, and to examine barriers to societal integration as a potential explanation for any observed disparities over-and-above the influence of established contributors to sexual orientation disparity in suicidality.

Methods Data come from the cross-sectional Swedish National Public Health Survey, which collected data from unrestricted random samples of individuals (16-84 years of age) living in Sweden, annually from 2010 to 2015 ( $n=57,840$ individuals [response rates: $48.1-51.3 \%$ ]; 1281 (2.2\%) self-identified as LGB). Analyses examined sexual orientation differences in suicidality (i.e., past-12-month ideation and attempts), and explored the role of barriers to societal integration (i.e., not living with a partner or children, unemployment, and lack of societal trust) in explaining this disparity over-and-above more commonly explored psychological (e.g., depression, substance use) and interpersonal (e.g., discrimination, victimization, lack of social support) suicidality risk factors.

Results Compared to heterosexuals, suicidal ideation and attempts were more common among both gay men/lesbians (adjusted odds ratio [AOR] for suicide ideation: 2.69; 95\% confidence intervals [CI]: 2.09, 3.47; AOR for suicide attempts: 5.50; 95\% CI: 3.42, 8.83), and bisexuals (AOR for suicide ideation: 3.83; 95\% CI: 3.26, 4.51; AOR suicide attempts: 6.78; 95\% CI: 4.97, 9.24). Barriers to societal integration mediated the association between sexual orientation and suicidality even in models adjusting for established risk factors for suicidality.

Conclusion Our results suggest that previously under-examined factors, namely the disproportionate barriers to societal integration that LGB individuals experience, are important contributors to the substantially elevated risk of suicidality among sexual minorities. Preventive interventions should consider innovative ways to foster societal integration within sexual minority populations and to adjust hetero-centric social institutions to better include sexual minority individuals.
\end{abstract}

Keywords Suicidality $\cdot$ Sexual minority $\cdot$ Lesbian, gay, bisexual $\cdot$ Minority stress $\cdot$ Social isolation

Electronic supplementary material The online version of this article (https://doi.org/10.1007/s00127-019-01742-6) contains supplementary material, which is available to authorized users.

Richard Bränström

richard.branstrom@ki.se

1 Department of Social and Behavioral Sciences, Yale School of Public Health, New Haven, CT, USA

2 Department of Clinical Neuroscience, Karolinska Institutet, Nobels väg 9, 17177 Stockholm, Sweden
"The bond that unites them with the common cause attaches them to life and the lofty goal they envisage prevents their feeling personal troubles so deeply."

Émile Durkheim, Suicide: A Study in Sociology (1897)

Across studies worldwide, sexual minority individuals (e.g., individuals who identify as lesbian, gay, and bisexual [LGB] or engage in same-sex sexual behavior) are significantly more likely to report suicidal thoughts and to attempt suicide than heterosexuals [1-5]. This disparity is 
accompanied by disparities in known risk factors for suicide, including depression [6-9] and substance abuse [9-11].

Several theoretical models, primarily focused on stigmarelated psychosocial and interpersonal stressors, have been used to explain the sexual orientation disparity in suicidality. For instance, many studies find that sexual minority individuals' increased exposure to interpersonal stressors related to their devalued sexual orientation, also known as minority stress, is a major contributor to the increased risk in this group compared to heterosexuals [11-14]. Studies have found that sexual minorities' higher exposure to minority stressors compared to heterosexuals, including discrimination $[9,15]$, victimization $[9,11,16]$, and lack of social support [11, 16, 17], may partly account for the sexual orientation disparity in suicidality $[18,19]$. Other general theoretical models of suicidality have been applied to explain the increased risk among sexual minority individuals [19]. For instance, both the clinical model of suicide behavior [20] and the interpersonal theory of suicide [21] emphasize psychological and interpersonal factors such as depression, substance abuse, perceived burdensomeness, loneliness, and thwarted belongingness as important explanatory risks for suicide. Several of these factors are elevated among sexual minority individuals and explain the increased risk of suicidality within this group [19], although not fully [22-24]. The fact that the sexual orientation disparity remains even in studies controlling for established risks factors that are elevated among sexual minorities motivates the search for additional sources of this disparity.

Less explored in the context of sexual orientation disparities in suicidality are sociological factors relating to a mismatch between an individual and their society. Already in the 19th century, Émile Durkheim suggested that an important precursor to suicide is a person's lack of integration within society and a lack of societal attachments and commitments [25]. He believed that insufficient societal integration, in the form of a lack of identification with societal norms, values, and goals, can leave people with little social guidance or support, and therefore, at increased risk of suicide. Accordingly, he found that barriers to societal integration associated with suicide can include being unmarried or living without a partner, not having children, being unemployed, and experiencing low societal trust. Durkheim's early findings of the importance of barriers to societal integration as risk factors for suicide have been confirmed in numerous later studies [26-31]. Whereas interpersonal factors like discrimination, victimization, and lack of social support involve psychological and social risks for suicide, barriers to societal integration represent sociological risks reflecting one's lack of attachment to society as a whole.

The present study takes advantage of the populationbased Swedish National Public Health Survey conducted between 2010 and 2015. The large sample size and representative data permitted us to determine whether barriers to societal integration (i.e., being unmarried/not living with a partner, not having children, being unemployed, and experiencing low societal trust) explain, or partially explain, sexual orientation disparities in suicidality independent of other established suicide risk factors, including psychological (i.e., depression, substance abuse) and interpersonal (i.e., discrimination, victimization, and lack of social support) risks. Findings have potential to expand theoretical and intervention considerations to largely overlooked determinants of this substantial public health problem.

\section{Method}

\section{Study sample}

Between 2010 and 2015, the Swedish National Institute of Public Health administered annual nationwide population-based health surveys to unrestricted random samples ( $n=20,000$ per year) of the Swedish population, $16-84$ years of age, identified through the comprehensive population registers available in Sweden. The overall response rate was between 48.1 and $51.3 \%$ each year, and it was higher among women and older age groups. A total of 57,840 individuals returned the questionnaires across the six surveys with complete responses on all key variables included in the current study. Identical modes of data collection and survey administration were used in all six surveys, and participants were offered the option to respond to the questions via paper-andpencil mailed questionnaires or self-administered web surveys. To adjust the results for varying response rates, poststratification weights were used to compensate for lower response rates in some groups, making the sample representative of the national population. In addition to a question regarding sexual orientation, the survey included questions broadly related to socio-demographic background, health status, and health determinants, and was supplemented with data from administrative national registries regarding marriage/partnership status, income, ethnicity, and urbanicity. The study was approved by the Regional Ethics Committee in Stockholm (No. 2013/2200-31/2).

\section{Measures}

\section{Sexual orientation}

Individuals were classified based on self-identification of sexual orientation using the following item: "What is your sexual orientation?" with the response categories commonly used in Swedish society: "heterosexual," "bisexual," "homosexual," and "not sure." The response rate for this question was between 93.7 and $96.8 \%$ across years, with $443(0.8)$ 
individuals self-identifying as gay/lesbian and $838(1.4 \%)$ self-identifying as bisexual. We excluded $1212(2.1 \%)$ individuals who responded that they were uncertain of their sexual orientation, as previous studies have shown that this group often consists of a heterogeneous mix of respondents in terms of sexual identity [32], including many who report not understanding the question [33]. Those who responded that they were unsure of their sexual orientation did not differ significantly in age from heterosexuals, but were more likely to be men, be born outside of Sweden, have lower income, and report poor general health, and less likely to be married or partnered, compared to heterosexuals.

\section{Suicidality}

We examined two measures of suicidality: (1) past 12-month suicidal ideation, and (2) past 12-month suicide attempt. Suicidal ideation was assessed with a single item: "Have you at any time in the last 12 months been in a situation where you have seriously considered taking your own life?" and response options included: 'no', 'yes, once', 'yes, several times.' The participants were categorized into two groups based on their response (i.e., 'no past 12-month suicidal ideation' or 'any past 12-month suicidal ideation'). Suicide attempt was assessed with a single item: "Have you at any time in the last 12 months attempted to take your own life?" and response options included: 'no', 'yes, once', 'yes, several times.' Participants were categorized into two groups based on their response (i.e., 'no past 12-month suicide attempt' or 'any past 12-month suicide attempt').

\section{Barriers to societal integration}

Barriers to societal integration factors are distinct from more commonly examined psychological and social support factors, as they relate to an individual's degree of assimilation with society's norms and expectations rather than one's internal psychological experience and the quality of interpersonal relationships. Barriers to societal integration were operationalized as four variables: being unmarried or not living with a partner, not living with children, lack of societal trust, and being unemployed. Marriage/partnership status was collected from the national registries and linked to the survey data. This information was used in combination with self-reported relationship status to categorize all married or registered partners and participants living with a partner into one category, and unmarried/unpartnered individuals and those not living with a partner into another category. Information on self-reported household composition was used to categorize participants as living with children or not. Societal trust was assessed with the question: "Do you think that people generally can rely on other people?" ['No;' 'Yes']; participants were categorized as lacking societal trust if they responded 'no.' Unemployment was assessed using a self-report question regarding current employment status.

\section{Psychological risk factors}

Two psychological risk factors for suicidality were assessed, namely depression symptoms and substance abuse. Depression symptoms were measured with the 12-item General Health Questionnaire (GHQ-12), a frequently used measure of current depression. The GHQ-12 focuses on two major types of symptoms: the inability to carry out normal functions (e.g., "Over the past few weeks, have you been able to enjoy your normal day-to-day activities?" with response alternatives: 'more so than usual,' 'same as usual'; 'less so than usual,' and 'much less than usual') and the presence of distressing experiences (e.g., "Over the past few weeks, have you been feeling unhappy and depressed?" with response alternatives: 'not at all,' 'no more than usual,' 'rather more than usual,' and 'much more than usual'). The GHQ-12 has shown adequate validity in both clinical and general samples and has demonstrated satisfactory sensitivity and specificity for predicting current major depression diagnosis [34, 35]. Consistent with prior literature [35], we created a dichotomous variable (GHQ12 $\leq 3$ : 'no current mental disorder,' GHQ12 $\geq 4$ : 'current mental disorder'). Substance abuse was assessed as past-12-month high-risk alcohol consumption or any cannabis use and was coded dichotomously (i.e., any use; no use). Two different measures were used to categorize respondents into high-risk versus non-high-risk consumers of alcohol. The first concerned average frequency of heavy drinking during the past 12 months, based on one question regarding drinking at least one bottle of wine or equivalent during one occasion. The second measure concerned total weekly amount of alcohol consumed on average during the past 12 months, measured as number of "drinks" (defined as 33 centiliters [cl] of beer, 10-15 $\mathrm{cl}$ of wine, $4 \mathrm{cl}$ of hard liquor, or equivalent). Male respondents were categorized as high-risk consumers of alcohol if they either reported at least monthly heavy alcohol consumption or reported an average weekly consumption of more than 14 drinks, in accordance with the standard threshold for hazardous weekly alcohol consumption [36]. Women were similarly categorized as high-risk consumers of alcohol if they either reported at least monthly heavy alcohol consumption or reported an average weekly consumption of more than 9 drinks. Cannabis use was assessed with one question regarding frequency of cannabis use during the past 12 months, which was categorized based on any past-12-month use (use; no use).

\section{Interpersonal risk factors}

Three potential interpersonal risk factors for suicide were assessed: exposure to discrimination, victimization or 
threat of assault, and lack of social support. Exposure to discrimination during the past 3 months was assessed with one question ("During the past 3 months, have you been treated in a way that made you feel discriminated against?" ['No;' 'Yes']). Victimization or threats of assault during the past 12 months was assessed with two questions ("During the past 12 months, have you been exposed to physical violence?" ['No;' 'Yes']; "During the past 12 months, have you been exposed to a threat or threats of violence in a way that made you scared?" ['No;' 'Yes']). Lack of social support was assessed with two questions: "Do you have anyone you can share your innermost feeling with and confide in? [ 'No;' 'Yes'] and "Can you get help from any person or persons if you have practical problems or are ill?" ['No;' 'Yes']). Participants were categorized as not having access to social support if they responded 'yes' to either or both of these questions.

\section{Covariates}

Socio-demographic factors were used as covariates and included age, gender, annual individual income, level of education, ethnicity (nation of birth categorized into groups of geographic regions), and urbanicity (living in a larger city, smaller city, or rural community).

\section{Statistical analysis}

After examining descriptive statistics of participants' sociodemographic characteristics, we used logistic regressions to estimate sexual orientation differences in suicidality, psychological and interpersonal risk factors, and barriers to societal integration. These analyses were adjusted for a number of covariates (i.e., age, gender, level of education, individual income, urbanicity, and country of birth). Next, we examined whether psychological and interpersonal risk factors and barriers to societal integration explained or partially explained sexual orientation disparities in suicidality using multiple mediation analyses. We conducted two separate multiple mediation analyses, one for suicide ideation and one for suicide attempts. For both multiple mediation analyses, all nine proposed mediating variables were included (i.e., depression, substance abuse, discrimination, victimization/threats, lack of social support, not married/ living with a partner, not living with a child, lack of societal trust, and unemployment). To statistically test mediation, we calculated the indirect effects of each variable as a mediator of the link between sexual orientation and suicidality. A significant indirect effect $(p<0.05)$ was interpreted as evidence of mediation.

To provide information regarding the relative explanatory potential of our variables, we calculated the unique proportion of the sexual orientation disparity that was explained by each block of mediators (i.e., psychological risks, interpersonal risks, and barriers to societal integration). We examined the contribution of each block of mediators both on its own and also in the context of the others, using calculation of risk differences as suggested by VanderWeele [37]. To assess the degree to which the results of our multiple mediation analyses were influenced by correlations between the covariates and our proposed mediators, we also conducted the multiple mediation analyses without adjustment for level of education, individual income, and urbanicity. Subpopulation effects were examined by performing mediation analyses separately for gay/lesbians and bisexuals.

In all analyses, post-stratification weights were used to adjust for selection probabilities and non-response. The weights were calculated to adjust for differences in response rates based on gender, age, country of birth (i.e., born in Sweden vs. non-Swedish born), as well as, level of education, and were used to generate nationally representative estimates of associations [38]. Analyses were performed using SPSS version 24 and Mplus Version 8.

\section{Results}

\section{Descriptive statistics}

Table 1 presents socio-demographic characteristics in the total sample stratified by gender and sexual orientation. Both gay men and lesbian women were more likely to be younger, university educated, born outside of Sweden, living in a larger city, compared to heterosexuals. Bisexuals were more likely to be younger, born outside of Sweden, living in a larger city, and to have lower income, compared to heterosexuals.

\section{Sexual orientation disparities in suicidality and suicidality risk factors}

Prevalence and odds ratios for sexual orientation differences in suicide ideation and suicide attempts during the past 12-month, as well as the proposed risk factors for suicidality, are presented in Table 2. Past 12-month suicide ideation and attempts were more common among both gay/lesbians and bisexual as compared to heterosexuals. Among gay/lesbians, all psychological and interpersonal risk factors for suicidality, as well as, not being married or living with a partner, not living with children, and lack of societal trust, were more common as compared to heterosexuals. Among bisexuals, all suggested psychological, interpersonal, and barriers to societal integration risk factors for suicidality were more common as compared to heterosexuals. 
Table 1 Sample characteristics by gender and sexual orientation in the Swedish National Public Health Survey, 2010 to 2015

\begin{tabular}{|c|c|c|c|c|c|c|c|c|}
\hline & Men & & & & Women & & & \\
\hline & Gay, $n=269$ & $\begin{array}{l}\text { Bisexual, } \\
n=286\end{array}$ & $\begin{array}{l}\text { Heterosexual, } \\
n=26,024\end{array}$ & & $\begin{array}{l}\text { Lesbian, } \\
n=174\end{array}$ & $\begin{array}{l}\text { Bisexual, } \\
n=552\end{array}$ & $\begin{array}{l}\text { Heterosexual, } \\
n=30,535\end{array}$ & \\
\hline Age, years & $n\left(\%^{\mathrm{a}}\right)$ & $n\left(\%^{\mathrm{a}}\right)$ & $n\left(\%^{\mathrm{a}}\right)$ & & $n\left(\%^{\mathrm{a}}\right)$ & $n\left(\%^{\mathrm{a}}\right)$ & $n\left(\%^{\mathrm{a}}\right)$ & \\
\hline $16-20$ & $15(1.2)$ & $40(3.2)$ & 1183 (95.6) & $F^{\mathrm{b}}=187.26^{* * *}$ & $15(1.0)$ & $78(4.9)$ & $1470(94.1)$ & $F^{\mathrm{c}}=582.92 * * *$ \\
\hline $21-25$ & 25 (1.9) & $30(2.2)$ & $1298(95.9)$ & & $13(0.7)$ & $106(6.1)$ & $1706(93.2)$ & \\
\hline $26-30$ & $24(2.1)$ & $18(1.3)$ & 1290 (96.6) & & $21(1.2)$ & $95(5.1)$ & 1747 (93.7) & \\
\hline $31-35$ & $31(2.0)$ & $22(1.4)$ & $1512(96.7)$ & & $24(1.3)$ & $66(3.4)$ & $1944(95.3)$ & \\
\hline $36-40$ & $61(1.7)$ & $40(1.1)$ & $3776(97.2)$ & & $42(0.9)$ & $96(2.1)$ & $4631(97.0)$ & \\
\hline $41-55$ & $41(0.9)$ & $46(1.1)$ & 4445 (97.9) & & $27(0.5)$ & $45(0.9)$ & $5400(98.5)$ & \\
\hline $56-84$ & $72(0.6)$ & $90(0.7)$ & $12,520(98.6)$ & & $32(0.2)$ & $66(0.5)$ & $13,637(99.3)$ & \\
\hline $\begin{array}{l}\text { Individual } \\
\text { income }\end{array}$ & $\mathrm{M}(\mathrm{SD})^{\mathrm{d}}$ & $M(S D)^{d}$ & $\mathrm{M}(\mathrm{SD})^{\mathrm{d}}$ & & $\mathrm{M}(\mathrm{SD})^{\mathrm{d}}$ & $\mathrm{M}(\mathrm{SD})^{\mathrm{d}}$ & $M(S D)^{d}$ & \\
\hline $\begin{array}{l}\text { Mean yearly } \\
\text { income in } \\
\mathrm{tSEK}^{\mathrm{e}}\end{array}$ & 202 (156) & $171(215)$ & $242(310)$ & $F=12.29 * * *$ & $168(131)$ & $126(104)$ & 189 (206) & $F=28.65 * * *$ \\
\hline Education & $n\left(\%^{\mathrm{a}}\right)$ & $n\left(\%^{\mathrm{a}}\right)$ & $n\left(\%^{\mathrm{a}}\right)$ & & $n\left(\%^{\mathrm{a}}\right)$ & $n\left(\%^{\mathrm{a}}\right)$ & $n\left(\%^{\mathrm{a}}\right)$ & \\
\hline $\begin{array}{l}\text { University } \\
\text { degree }\end{array}$ & $138(45.2)$ & $102(30.6)$ & 9147 (31.0) & $\mathrm{Chi}^{2}=33.19 * * *$ & $79(41.0)$ & $235(36.1)$ & $12,817(36.4)$ & $\mathrm{Chi}^{2}=1.66$ \\
\hline Urbanicity & $n\left(\%^{\mathrm{a}}\right)$ & $n\left(\%^{\mathrm{a}}\right)$ & $n\left(\%^{\mathrm{a}}\right)$ & & $n\left(\%^{\mathrm{a}}\right)$ & $n\left(\%^{\mathrm{a}}\right)$ & $n\left(\%^{\mathrm{a}}\right)$ & \\
\hline Larger city & $148(53.4)$ & 104 (39.7) & 7740 (31.5) & $\mathrm{Chi}^{2}=109.20^{* * *}$ & $88(50.8)$ & 215 (39.6) & 9399 (31.9) & $\mathrm{Chi}^{2}=46.35^{* * *}$ \\
\hline Smaller city & $74(29.2)$ & $101(35.3)$ & 8468 (32.2) & & $41(24.6)$ & $157(27.7)$ & $9991(32.0)$ & \\
\hline $\begin{array}{l}\text { Rural com- } \\
\text { munity }\end{array}$ & $47(17.4)$ & $81(25.1)$ & $9816(36.4)$ & & $45(24.6)$ & $180(32.6)$ & $11,145(36.2)$ & \\
\hline $\begin{array}{l}\text { Nation of } \\
\text { birth }\end{array}$ & $n\left(\%^{\mathrm{a}}\right)$ & $n\left(\%^{\mathrm{a}}\right)$ & $n\left(\%^{\mathrm{a}}\right)$ & & $n\left(\%^{\mathrm{a}}\right)$ & $n\left(\%^{\mathrm{a}}\right)$ & $n\left(\%^{\mathrm{a}}\right)$ & \\
\hline Sweden & 203 (68.9) & $233(77.4)$ & $23,263(85.7)$ & $\mathrm{Chi}^{2}=104.37 * * *$ & 145 (76.9) & $468(81.2)$ & $27,149(84.8)$ & $\mathrm{Chi}^{2}=43.52 * * *$ \\
\hline $\begin{array}{l}\text { Other Nordic } \\
\text { Country }\end{array}$ & $15(5.6)$ & $9(2.8)$ & 763 (2.9) & & $5(3.3)$ & $12(2.1)$ & $1083(3.7)$ & \\
\hline $\begin{array}{l}\text { Other } \\
\text { European } \\
\text { Country }\end{array}$ & $27(12.3)$ & $21(8.3)$ & $1017(5.3)$ & & $11(7.7)$ & $47(10.3)$ & $1192(5.5)$ & \\
\hline $\begin{array}{l}\text { Non- } \\
\text { European } \\
\text { Country }\end{array}$ & $24(13.2)$ & 23 (11.6) & $981(6.2)$ & & $13(12.1)$ & $25(6.4)$ & $1111(6.1)$ & \\
\hline
\end{tabular}

*Significant at $p<0.05, * *$ significant at $p<0.01 ; * *$ significant at $p<0.001$

${ }^{a}$ Weighted percentages

${ }^{b}$ Mean age for gay $(m e a n=39.6, \mathrm{SD}=15.4)$ and bisexual (mean $\left.=38.9, \mathrm{SD}=18.3\right)$ men were significantly lower than for heterosexual men $($ mean $=47.0, \mathrm{SD}=18.0)$

${ }^{\mathrm{c} B i s e x u a l}$ women were significantly younger (mean $\left.=32.5, \mathrm{SD}=13.5\right)$ than lesbian $($ mean $=38.1, \mathrm{SD}=15.1)$ and heterosexual women ( $m e a n=48.0, \mathrm{SD}=18.1$ ), and lesbians were significantly younger than heterosexual women

${ }^{\mathrm{d}}$ Weighted means and standard deviations

${ }^{\mathrm{e}} \mathrm{Swedish}$ kronor, in thousands

\section{Mediators of sexual orientation disparities in suicidality}

Test of mediation was first conducted using an approach whereby groups of suggested mediators were entered in three separate blocks: (1) psychological risk factors, (2) interpersonal risk factors, and (3) barriers to societal integration. Secondly, all three blocks were entered as mediators in a full mediation model. For the first block, the indirect mediating effects of depression and substance abuse for both gay/lesbians and bisexuals were significant, suggesting that these factors partially mediated the sexual orientation disparity in suicidality and explained $35.9 \%$ of the variance in suicide ideation and $26.3 \%$ of the variance in suicide attempts. For the second block, the indirect mediating effects of all interpersonal risk factors were significant, 
Table 2 Logistic regressions with associations between sexual orientation and past 12-month suicidal ideation and attempts, psychological and interpersonal risk factors, and barriers to societal integration

\begin{tabular}{|c|c|c|c|c|c|c|}
\hline & \multicolumn{3}{|c|}{ Descriptive results } & \multicolumn{3}{|c|}{ Logistic regression results } \\
\hline & $\begin{array}{l}\text { Heterosexual } \\
n(\%)^{\mathrm{a}}\end{array}$ & $\begin{array}{l}\text { Gay/lesbian } \\
n(\%)^{\mathrm{a}}\end{array}$ & $\begin{array}{l}\text { Bisexual } \\
n(\%)^{\mathrm{a}}\end{array}$ & $\begin{array}{l}\text { Heterosexual } \\
\text { (Reference) }\end{array}$ & $\begin{array}{l}\text { Gay/lesbian } \\
\operatorname{AOR}^{\mathrm{b}}(95 \% \mathrm{CI})\end{array}$ & $\begin{array}{l}\text { Bisexual } \\
\operatorname{AOR}^{\mathrm{b}}(95 \% \mathrm{CI})\end{array}$ \\
\hline \multicolumn{7}{|l|}{ Suicidality } \\
\hline Suicide ideation, past 12 months & $2409(5.0)$ & $55(14.1)$ & $170(22.4)$ & 1 & $2.69 * * *(2.09,3.47)$ & $3.83 * * *(3.26,4.51)$ \\
\hline Suicide attempts, past 12 months & $232(0.6)$ & $13(3.9)$ & $41(5.6)$ & 1 & $5.50 * * *(3.42,8.83)$ & $6.78 * * *(4.97,9.24)$ \\
\hline \multicolumn{7}{|l|}{ Psychological risk factors } \\
\hline Depression symptoms & $6363(12.3)$ & $72(17.8)$ & $227(29.3)$ & 1 & $1.33 *(1.06,1.68)$ & $2.23 * * *(1.93,2.59)$ \\
\hline Substance abuse & $9285(18.5)$ & $112(28.9)$ & $200(25.8)$ & 1 & $1.43 * * *(1.17,1.74)$ & $1.36^{* * *}(1.17,1.59)$ \\
\hline \multicolumn{7}{|l|}{ Interpersonal risk factors } \\
\hline Discrimination & $9928(19.0)$ & $133(33.3)$ & $330(41.5)$ & 1 & $1.93 * * *(1.60,2.33)$ & $2.11 * * *(1.85,2.42)$ \\
\hline Victimization and threats & $2646(5.5)$ & $39(9.3)$ & $107(13.7)$ & 1 & $1.38 *(1.03,1.87)$ & $1.95 * * *(1.61,2.36)$ \\
\hline Lack of social support & $2300(4.4)$ & $41(10.4)$ & $72(9.1)$ & 1 & $2.12 * * *(1.51,2.96)$ & $2.29 * * *(1.78,2.95)$ \\
\hline \multicolumn{7}{|l|}{ Barriers to societal integration } \\
\hline Not married or living with a partner & $17,167(34.9)$ & $207(50.4)$ & $429(55.6)$ & 1 & $1.63 * * *(1.35,1.96)$ & $1.51 * * *(1.31,1.73)$ \\
\hline Not living with children & $41,281(72.1)$ & $389(88.0)$ & $639(77.9)$ & 1 & $3.69 * * *(2.80,4.86)$ & $1.43 * * *(1.21,1.68)$ \\
\hline Lack of societal trust & $12,227(25.3)$ & $135(33.4)$ & $319(41.5)$ & 1 & $1.24 *(1.02,1.50)$ & $1.53 * * *(1.33,1.75)$ \\
\hline Being unemployed & $1951(4.4)$ & $27(7.8)$ & $83(10.8)$ & 1 & $1.32(0.94,1.85)$ & $1.72 * * *(1.39,2.13)$ \\
\hline
\end{tabular}

*Significant at $p<0.05 ; * *$ Significant at $p<0.01 ; * * *$ Significant at $p<0.001$

${ }^{a}$ Weighted percentages

${ }^{\mathrm{b}}$ Analyses were adjusted for age, gender, level of education, individual income, urbanicity, and country of birth

suggesting that interpersonal risk factors partially mediated the sexual orientation disparity in suicidality, and, explained $46.2 \%$ of the variance in suicide ideation and $41.0 \%$ of the variance in suicide attempts. For the third block, the indirect mediating effect of all barriers to societal integration were significant, suggesting that barriers to societal integration significantly mediated the sexual orientation disparity in suicidality, and, explained $34.4 \%$ of the variance in suicide ideation and $36.0 \%$ of the variance in suicide attempts.

Figure 1 contains results from the full multiple mediation analyses examining psychological risk factors, interpersonal risk factors, and barriers to societal integration as mediators of the sexual orientation disparity in suicidality. In this full model, we calculated the unique proportion of the sexual orientation disparity mediated by each block of mediators, separately for gay men/lesbians and bisexuals, using calculation of risk differences as suggested by VanderWeele [37]. In analyses examining the disparities between gay men and lesbians compared to heterosexuals, the psychological risk factors explained $23.1 \%$ of the disparity in suicide ideation and $16.5 \%$ in suicide attempts; the interpersonal risk factors explained $52.0 \%$ of the disparity in suicide ideation and $42.3 \%$ of the disparity in suicide attempts; and the barriers to societal integration factors explained $32.4 \%$ of the disparity in suicide ideation and $29.2 \%$ of the disparity in suicide attempts. [37]. In analyses examining the disparities between bisexuals compared to heterosexuals, the psychological risk factors explained $38.7 \%$ of the disparity in suicide ideation and $31.8 \%$ in suicide attempts; the interpersonal risk factors explained $52.6 \%$ of the disparity in suicide ideation and $47.5 \%$ of the disparity in suicide attempts; and the barriers to societal integration factors explained $30.4 \%$ of the disparity in suicide ideation and $27.2 \%$ of the disparity in suicide attempts. Total proportions explained can be greater than $100 \%$ in circumstances in which the controlled direct effect and the indirect effects are operating in opposite directions [37].

The full multiple medication analyses were adjusted for a number of covariates, including level of education, individual income, and urbanicity. These variables were treated as covariates rather than potential mediators since we had no strong reason, based on existing research, to believe that they would fall along the causal path. Lacking evidence for a causal role of sexual minority identity on social or geographic mobility [39], we instead assumed that level of education, individual income, and urbanicity, which tend to be associated with support for sexual minority populations and rights [40, 41], would precede sexual minority identity. To assess the degree to which the results of our multiple mediation analyses were influenced by correlations between these covariates and our proposed mediators, we conducted the multiple mediation analyses without adjustment for level of education, individual income, and urbanicity. These analyses resulted in near-identical results (see online supplementary 


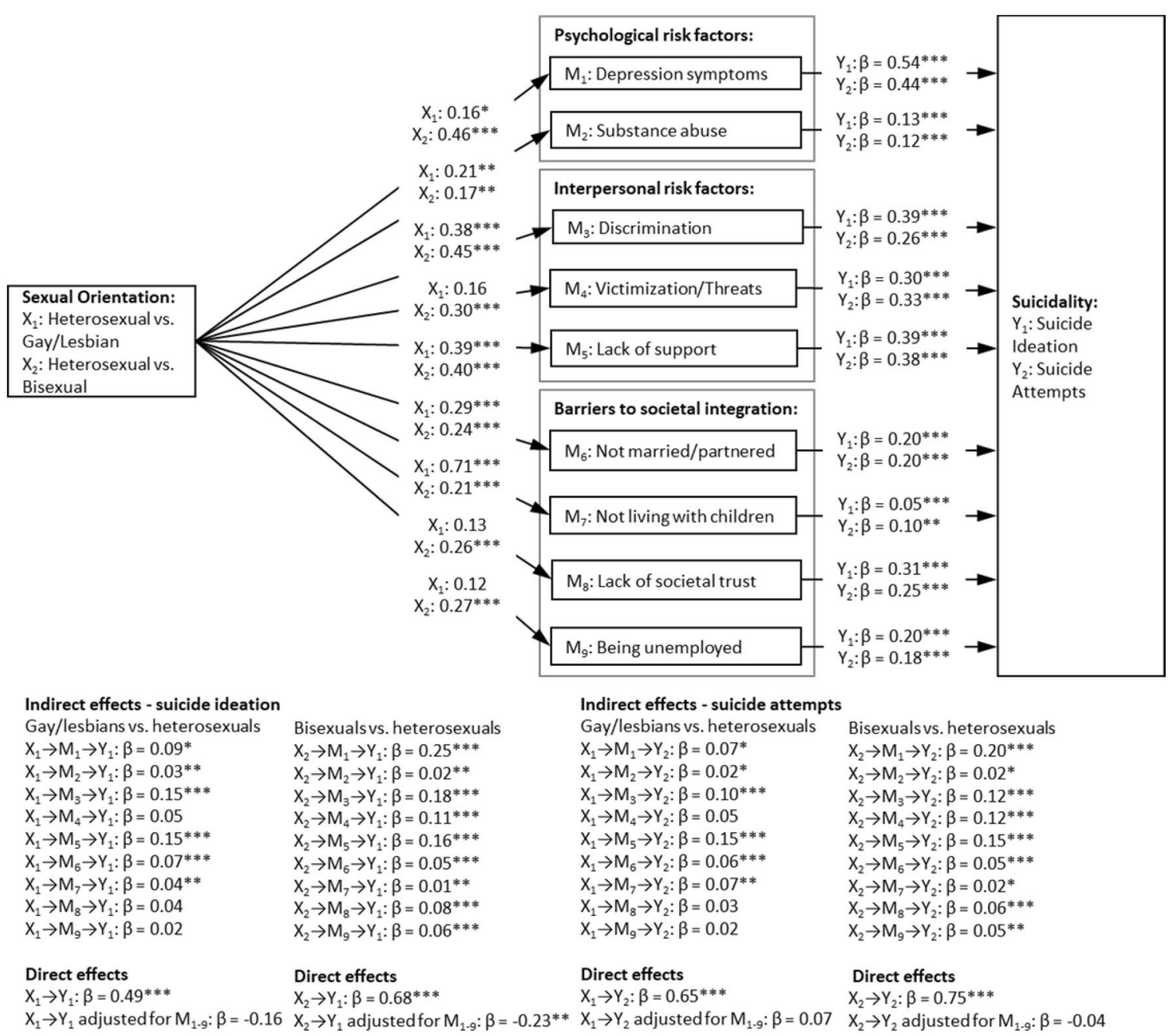

Fig. 1 Indirect and direct effect of sexual orientation differences in suicidality mediated through psychological and interpersonal risk factors and barriers to societal integration

Figure A). The correlations among all proposed mediator variables are presented in online supplementary Table A.

\section{Discussion}

This population-based study suggests that barriers to societal integration represent an under-investigated mechanism of the sizeable sexual orientation disparity in suicidality. Results suggest that the substantially elevated risk of suicidality among sexual minorities can only be partially explained by increased exposure to commonly investigated psychological (e.g., depression, substance use) and interpersonal (e.g., discrimination, victimization/threats, lack of social support) stressors; even in analyses controlling for these factors, all sexual minority groups still demonstrated greater risk of past-12-month suicidal attempts than heterosexuals. The present study extends existing research into causes of the higher prevalence of suicidality among sexual minorities to sociological factors disproportionally affecting sexual minorities, namely barriers to societal integration, which further explain this population's disproportionate risk of suicide. By considering barriers to societal integration in the context of more-traditionally examined interpersonal factors (e.g., experiences of discrimination), psychological factors (e.g., depression), and demographic covariates, this population-based study captures a fuller set of possible predictors of this pressing public health problem than has been historically examined.

Our study confirms the substantial role that sexual minorities' disproportionate exposure to psychological (e.g., depression, substance use) and interpersonal (e.g., discrimination, victimization, lack of social support) risk factors play in their disparate risk of suicidality. Consistent with minority stress theory $[12,14]$, stigma and discrimination place sexual minorities at elevated risk of depression, 
substance use, and social isolation, all of which etiologically contribute to suicidality. While empirical research supports the association between these types of risks and suicidality among sexual minorities [42, 43], the sexual orientation disparity remains even when controlling for these risks [22-24], suggesting the need to search for additional sources of this disparity.

The present study finds support for a set of largely overlooked sociological mediators of the sexual orientation disparity in suicidality. While previously unexplored as applied to sexual orientation disparities in suicidality, barriers to societal integration (i.e., not living with a partner or children, unemployment, and lack of societal trust) represent some of the earliest determinants to be investigated in the suicide literature. In fact, in one of the earliest monographs in the field of sociology, Émile Durkheim (1897) concluded, from his detailed case studies of suicide, that suicide was the result of sociological factors like these. Specifically, he proposed that suicide results from a mismatch between an individual's personal goals and values and societal opportunities to fulfill and support those goals and values. Such a mismatch, he argued, is most pronounced under conditions of rapid societal change or among otherwise alienated social groups, in which some individuals (e.g., those without children, the unmarried, those who have rapidly accumulated or lost wealth) are at risk of being untethered to the predominant societal structures that function to provide meaning and purpose. Sexual minorities, while not the focus of Durkheim's treatise, have often forged relatively uncharted life paths in modern times [44]. At the same time that the social creativity required to organize a life outside of mainstream templates represents a resilient feature of many sexual minority communities [45], a lack of societal opportunity or support for fulfilling those goals can theoretically lead to the type of existential despair uncovered by Durkheim as a defining sociological feature of suicide risk.

In the present study, we in fact found that, compared to heterosexuals, sexual minorities exhibit higher barriers to societal integration. Specifically, gay men and lesbians were more likely to not be married or live with a partner or children, whereas bisexual men and women were more likely to not be married or live with a partner or children, to be unemployed, and to report a lack of societal trust. These barriers are consistent with the sociological determinants of suicidality proposed by Durkheim over a century ago and take the search for reasons underlying this pressing public health problem to surprisingly overlooked territory. That these barriers statistically explained the sexual orientation disparity in suicidality even over-and-above more commonly investigated psychological and interpersonal factors suggest that they represent an important focus of future research and preventative interventions. When examined together, the full set of predictors examined here explained nearly all of the variance in the sexual orientation disparity in suicide. Rather than controlling for these factors to remove their influence, as is often done in sexual orientation disparities research [46, 47], researchers ought to seriously consider the possibility suggested here- that these barriers to societal integration represent heretofore overlooked factors potentially lying along the causal chain of risks disproportionately facing sexual minorities. That the disparity in suicidality between bisexuals and heterosexuals, compared to the disparity between gay men/lesbians and heterosexuals, was distinctly influenced by unemployment and low societal trust deserves future attention. Bisexuals represent a heterogeneous population that, on average, experiences lower community connection and sexual identity disclosure than gay men and lesbians [48]. Bisexuals are also exposed to unique forms of stigma-based stress including invisibility to heterosexual and gay/lesbian society [49]. These experiences are consistent with the barriers to societal integration examined here and deserve particular future attention given bisexual individuals' disproportionate risk of suicide even when compared to gay men and lesbians.

Recommending interventions based on these findings is complicated by the fact that the very features of sexual minority communities and cultures that put them at risk of falling outside the grasp of Durkheim's tethering societal structures have also positioned them as modern harbingers of future societal changes (e.g., activism for promoting greater flexibility and nuance in definitions of societal structures ranging from family to sexuality to gender). Based on our findings, we propose that for some sexual minorities, the price of challenging hegemonic lifestyles like marriage might be the existential despair that precedes suicide. From this, we recommend that preventative interventions support sexual minority communities in their vanguard role in challenging outdated or overly rigid definitions of societal meaning and purpose while at the same time ensuring that such pursuits themselves are valued and supported. Most concretely, being married, having children, and being employed should not be requisite of life itself, but this large representative study finds that these common social institutions might serve as an important protection against suicidality, disproportionately not attained by sexual minorities. Certainly, until relatively recently, discriminatory legislation in Sweden reduced sexual minorities' ability to marry or raise children. However, in Sweden today, fewer such structural discrimination barriers exist. At the same time, some sexual minorities simply do not desire to attain these roles, adopting instead distinct sexual minority deontologies formed in reaction to hegemonic heterosexual life paths. In working with individuals who do not form traditional societal attachments, whether due to stigma or by choice, mental health professionals might support the pursuit of meaning and purpose in other life domains (e.g., activism, community, chosen 
families). These findings also suggest that policy makers should seek to remove sexual minorities' inequitable barriers to achieving societal integration across the lifespan, including barriers to actual attainment (e.g., through second parent adoption, same-sex marriage) and barriers to aspiration (e.g., through role modeling and inclusive educational opportunities).

Despite the strength of the large nationally representative sample of sexual minorities that includes comprehensive measures of psychological, interpersonal, and sociological determinants of suicidality, study results should be considered in light of several limitations. First, the cross-sectional design did not enable us to make causal conclusion from our results. Although we treat our suggested societal integration variables as predictive risk factors and include them as mediators, rather than controlling for these factors as confounders, the causal inference suggested by this approach must be interpreted with this limitation in mind. While barriers to societal integration might temporally predict suicidality, perhaps suicidality or its etiological precursors might predict barriers to societal integration, a possibility which only longitudinal designs can further determine. However, it is improbable that suicidal attempts cause sexual orientation, mental health problems, or barriers to societal integration, or that mental health problems or barriers to societal integration cause sexual minority status, and no existing literature support such reverse causality. Second, only an age-period-cohort design can parse individual developmental influences from societal change as determinants of health disparities; findings from the present study are limited to the single snapshot of the population captured here. Third, this study relied on self-reported suicidal ideation and attempts. Without assessing completed suicides, results may be influenced by self-report bias, method invariance, or differential attrition due to suicide particularly likely to affect estimates for the oldest age groups. Fourth, Durkheim suggested other barriers to societal integration not capable of being examined with the current dataset. For instance, rapidly accumulated or lost wealth and lack of involvement in religious networks represent additional conditions of societal disintegration perhaps relevant to the sexual orientation disparity in suicide that await future examination. Finally, Sweden, like all countries, represents a distinct cultural context, in this case one notable for its progressive treatment of sexual minorities in recent decades $[8,50,51]$. Knowing how this particular national context might influence results demands future international comparisons. At the same time, the fact that these lifespan disparities in suicidality and barriers to societal integration exist in this most progressive context suggests that results might underestimate global trends.

In sum, the present study takes advantage of important methodological advances, namely a large nationally representative sample including measures of sexual identity and comprehensive measures of psychological, interpersonal, and sociological predictors of suicidality, to examine disparities and determinants of the sexual orientation disparity in suicidality. In addition to suggesting that sexual minorities are at substantially increased risk for suicidal ideation and attempts, our results link the epidemiologic study of this critical public health problem to among the earliest-investigated determinants of suicide for the general population. By highlighting the important role of barriers to societal integration (e.g., marriage/partnership, children, employment, societal trust) in explaining the sexual orientation disparity in suicide, results have potential to shift prevention resources to increasing equity in sources of life fulfillment, both common and path-breaking regardless of sexual identity.

Acknowledgement Open access funding provided by Karolinska Institute.

Funding This work was supported by the Swedish Research Council [2016-01707], the Swedish Research Council for Health, Working Life, and Welfare (Nr: 2014-0173; 2018-01628), and the Swedish National Research School of Health Care Science. The funding sources had no involvement in the study design, data collection, analyses, interpretation of data, or the reporting of findings.

\section{Compliance with ethical standards}

Conflict of interest The authors have no conflict of interest to disclose.

Ethics approval The study has been approved by the Regional Ethics Committee in Stockholm (No. 2013/2200-31/2).

Open Access This article is distributed under the terms of the Creative Commons Attribution 4.0 International License (http://creativeco mmons.org/licenses/by/4.0/), which permits unrestricted use, distribution, and reproduction in any medium, provided you give appropriate credit to the original author(s) and the source, provide a link to the Creative Commons license, and indicate if changes were made.

\section{References}

1. Miranda-Mendizabal A, Castellvi P, Pares-Badell O, Almenara J, Alonso I, Blasco MJ, Cebria A, Gabilondo A, Gili M, Lagares C, Piqueras JA, Roca M, Rodriguez-Marin J, Rodriguez-Jimenez T, Soto-Sanz V, Vilagut G, Alonso J (2017) Sexual orientation and suicidal behaviour in adolescents and young adults: systematic review and meta-analysist. Br J Psychiatry 211(2):77-87. https:// doi.org/10.1192/bjp.bp.116.196345

2. King M, Semlyen J, Tai SS, Killaspy H, Osborn D, Popelyuk D, Nazareth I (2008) A systematic review of mental disorder, suicide, and deliberate self harm in lesbian, gay and bisexual people. BMC Psychiatry 8(1):70

3. Björkenstam C, Kosidou K, Björkenstam E, Dalman C, Andersson G, Cochran S (2016) Self-reported suicide ideation and attempts, and medical care for intentional self-harm in lesbians, gays and bisexuals in Sweden. J Epidemiol Community Health. https://doi. org/10.1136/jech-2015-206884 
4. Hottes TS, Bogaert L, Rhodes AE, Brennan DJ, Gesink D (2016) Lifetime prevalence of suicide attempts among sexual minority adults by study sampling strategies: a systematic review and metaanalysis. Am J Public Health 106(5):e1-e12

5. Plöderl M, Tremblay P (2015) Mental health of sexual minorities. A systematic review. Int Rev Psychiatry (Abingdon, Engl) 27(5):367-385. https://doi.org/10.3109/09540261.2015.1083949

6. Donahue K, Långström N, Lundström S, Lichtenstein P, Forsman M (2017) Familial factors, victimization, and psychological health among sexual minority adolescents in Sweden. Am J Public Health 107(2):322-328

7. Frisell T, Lichtenstein P, Rahman Q, Långström N (2010) Psychiatric morbidity associated with same-sex sexual behaviour: influence of minority stress and familial factors. Psychol Med 40(2):315-324. https://doi.org/10.1017/s0033291709005996

8. Hatzenbuehler ML, Bränström R, Pachankis JE (2018) Societallevel explanations for reductions in sexual orientation mental health disparities: results from a ten-year, population-based study in Sweden. Stigma Health 3(1):16-26

9. Bränström R, Pachankis JE (2018) Sexual orientation disparities in the co-occurrence of substance use and psychological distress: a national population-based study. Soc Psychiatry Psychiatr Epidemiol 4(53):403-415

10. Bränström R, Hatzenbuehler ML, Tinghög P, Pachankis JE (2018) Sexual orientation differences in outpatient psychiatric treatment and antidepressant usage: evidence from a populationbased study of siblings. Eur J Epidemiol 33:591-599

11. Bränström R (2017) Minority stress factors as mediators of sexual orientation disparities in mental health treatment: a longitudinal population-based study. J Epidemiol Community Health 71(5):446-452. https://doi.org/10.1136/jech-2016-207943

12. Hatzenbuehler ML (2009) How does sexual minority stigma "get under the skin"? A psychological mediation framework. Psychol Bull 135(5):707-730. https://doi.org/10.1037/a0016441

13. Hong JS, Kral MJ, Sterzing PR (2015) Pathways from bullying perpetration, victimization, and bully victimization to suicidality among school-aged youth: a review of the potential mediators and a call for further investigation. Trauma Violence Abuse 16(4):379-390. https://doi.org/10.1177/1524838014537904

14. Meyer I (2003) Prejudice, social stress, and mental health in lesbian, gay, and bisexual populations: conceptual issues and research evidence. Psychol Bull 129(5):674-697. https://doi. org/10.1037/0033-2909.129.5.674

15. Axelsson J, Moden B, Rosvall M, Lindström M (2013) Sexual orientation and self-rated health: the role of social capital, offence, threat of violence, and violence. Scand J Public Health 41(5):508-515. https://doi.org/10.1177/1403494813476159

16. Balsam KF, Rothblum ED, Beauchaine TP (2005) Victimization over the life span: a comparison of lesbian, gay, bisexual, and heterosexual siblings. J Consult Clin Psychol 73(3):477-487. https://doi.org/10.1037/0022-006x.73.3.477

17. Bränström R, Pachankis JE (2018) Sexual orientation disparities in the co-occurrence of substance use and psychological distress: a national population-based study (2008-2015). Soc Psychiatry Psychiatr Epidemiol 53(4):403-412

18. Plöderl M, Fartacek R (2005) Suicidality and associated risk factors among lesbian, gay, and bisexual compared to heterosexual Austrian adults. Suicide Life Threat Behavior 35(6):661-670

19. Plöderl M, Sellmeier M, Fartacek C, Pichler E, Fartacek R, Kralovec K (2014) Explaining the suicide risk of sexual minority individuals by contrasting the minority stress model with suicide models. Arch Sex Behav 43(8):1559-1570

20. Mann JJ, Waternaux C, Haas GL, Malone KM (1999) Toward a clinical model of suicidal behavior in psychiatric patients. Am J Psychiatry 156(2):181-189
21. Van Orden KA, Witte TK, Cukrowicz KC, Braithwaite SR, Selby EA, Joiner TE Jr (2010) The interpersonal theory of suicide. Psychol Rev 117(2):575

22. Herrell R, Goldberg J, True WR, Ramakrishnan V, Lyons M, Eisen S, Tsuang MT (1999) Sexual orientation and suicidality: a co-twin control study in adult men. Arch Gen Psychiatry 56(10):867-874

23. Russell ST, Joyner K (2001) Adolescent sexual orientation and suicide risk: evidence from a national study. Am J Public Health 91(8):1276-1281

24. Safren SA, Heimberg RG (1999) Depression, hopelessness, suicidality, and related factors in sexual minority and heterosexual adolescents. J Consult Clin Psychol 67(6):859

25. Durkheim E (1897) Suicide: a study in sociology. Ancienne Librairie Germer Baillière, Paris

26. Fernquist RM, Cutright $P$ (1998) Societal integration and agestandardized suicide rates in 21 developed countries, 1955-1989. Soc Sci Res 27(2):109-127

27. Platt $S$ (1984) Unemployment and suicidal behaviour: a review of the literature. Soc Sci Med 19(2):93-115

28. Smith JC, Mercy JA, Conn JM (1988) Marital status and the risk of suicide. Am J Public Health 78(1):78-80

29. Yip PS, Thorburn J (2004) Marital status and the risk of suicide: experience from England and Wales, 1982-1996. Psychol Rep 94(2):401-407

30. Qin P, Agerbo E, Mortensen PB (2003) Suicide risk in relation to socioeconomic, demographic, psychiatric, and familial factors: a national register-based study of all suicides in Denmark, 1981-1997. Am J Psychiatry 160(4):765-772

31. Kelly BD, Davoren M, Mhaoláin ÁN, Breen EG, Casey P (2009) Social capital and suicide in 11 European countries: an ecological analysis. Soc Psychiatry Psychiatr Epidemiol 44(11):971

32. Sexual Minority Assessment Research Team [SMART] (2009) Best practices for asking questions about sexual orientation on surveys. The Williams Institute Los Angeles

33. Sell RL, Wells JA, Wypij D (1995) The prevalence of homosexual behavior and attraction in the United States, the United Kingdom and France: results of national population-based samples. Arch Sex Behav 24(3):235-248

34. Aalto AM, Elovainio M, Kivimaki M, Uutela A, Pirkola S (2012) The Beck Depression Inventory and General Health Questionnaire as measures of depression in the general population: a validation study using the Composite International Diagnostic Interview as the gold standard. Psychiatry Res 197(1-2):163-171. https://doi. org/10.1016/j.psychres.2011.09.008

35. Holi MM, Marttunen M, Aalberg V (2003) Comparison of the GHQ-36, the GHQ-12 and the SCL-90 as psychiatric screening instruments in the Finnish population. Nord J Psychiatry 57(3):233-238. https://doi.org/10.1080/08039480310001418

36. Swedish National Institute of Public Health (2010) The risk drinking project in Sweden. Alcohol prevention in primary health care and occupational health care. The Swedish National Institute of Public Health, Östersund, Sweden

37. Vanderweele TJ (2015) Explanation in causal inference: methods for mediation and intercation. Oxford University Press, New York

38. Lundström S, Särndal C-E (2002) Estimation in the presence of nonresponse and frame imperfections. Statistics Sweden, Stockholm, Sweden

39. Hatzenbuehler ML, Flores AR, Gates GJ (2017) Social attitudes regarding same-sex marriage and LGBT health disparities: results from a national probability sample. J Soc Issues 73(3):508-528

40. Baunach DM (2012) Changing same-sex marriage attitudes in America from 1988 through 2010. Public Opin Q 76(2):364-378

41. McVeigh R, Maria-Elena DD (2009) Voting to ban same-sex marriage: interests, values, and communities. Am Sociol Rev 74(6):891-915 
42. De Graaf R, Sandfort TG, ten Have M (2006) Suicidality and sexual orientation: differences between men and women in a general population-based sample from the Netherlands. Arch Sex Behav 35(3):253-262

43. Fergusson DM, Horwood LJ, Beautrais AL (1999) Is sexual orientation related to mental health problems and suicidality in young people? Arch Gen Psychiatry 56(10):876-880

44. Siegel S, Lowe E (1994) Uncharted lives: understanding the life passages of gay men. Dutton Adult, New York, USA

45. Herrick AL, Stall R, Goldhammer H, Egan JE, Mayer KH (2014) Resilience as a research framework and as a cornerstone of prevention research for gay and bisexual men: theory and evidence. AIDS Behav 18(1):1-9

46. Gilman SE, Cochran SD, Mays VM, Hughes M, Ostrow D, Kessler RC (2001) Risk of psychiatric disorders among individuals reporting same-sex sexual partners in the National Comorbidity Survey. Am J Public Health 91(6):933-939
47. Mays VM, Cochran SD (2001) Mental health correlates of perceived discrimination among lesbian, gay, and bisexual adults in the United States. Am J Public Health 91(11):1869-1876

48. Balsam KF, Mohr JJ (2007) Adaptation to sexual orientation stigma: a comparison of bisexual and lesbian/gay adults. J Couns Psychol 54(3):306

49. Ross LE, Salway T, Tarasoff LA, MacKay JM, Hawkins BW, Fehr CP (2018) Prevalence of depression and anxiety among bisexual people compared to gay, lesbian, and heterosexual individuals: a systematic review and meta-analysis. J Sex Res 55(4-5):435-456

50. Hooghe M, Meeusen C (2013) Is same-sex marriage legislation related to attitudes toward homosexuality? Trends in tolerance of homosexuality in european countries between 2002 and 2010. Sex Res Soc Policy 10:258-268

51. The Swedish Federation for LGBT Rights (2015) LGBT history: "HBT-historia". www.rfsl.se 